\title{
EL PRINCIPIO DE LEGALIDAD \\ Y LOS LÍMITES AL PODER PUNITIVO
}

MAURO BENENTE ${ }^{1}$

\section{RESUMEN}

Tanto la academia jurídica cuanto la jurisprudencia indica que el principio de legalidad es una garantía que limita el poder de castigar del Estado. En este trabajo me interesa rescatar el modo en que Raúl Zaffaroni y Luigi Ferrajoli exhiben al principio de legalidad como un dique de contención del poder de castigar. Luego, tras subrayar que el principio de legalidad fue incluido en el sistema legal por las mismas agencias que tienen el poder de castigar, realizo un abordaje de las obras de Beccaria y Feuerbach y sostengo que en sus conceptualizaciones el principio es un límite del poder de castigar, pero un límite que se ajusta perfectamente con las justificaciones del castigo.

PALABRAS CLAVE: Garantismo, poder punitivo, poder político, principio de legalidad, coacción psicológica.

1 Investigador del Instituto de Investigaciones Jurídicas y Sociales “A. L. Gioja." y Profesor Adjunto (int.) a cargo del curso "Michel Foucault, el derecho y el poder" en la Facultad de Derecho de la Universidad de Buenos Aires, y Profesor Titular de Filosofía del Derecho de la Universidad Nacional de José C. Paz. 


\section{ABSTRACT}

Both the legal academy as the case law indicates that the principle of legality is a guarantee that limits the State's power to punish. In this paper I want to emphasize how Raúl ZAFFARONI and Luigi FERRAJOLI display the principle of legality as a dam to the the power to punish. Then, after stressing that the principle of legality was included in the legal system by the same agencies that have the power to punish, I develop an approach to the works of BECCARIA and FEUERBACH, and I maintain that in their conceptualizations the principle is a limit to the power to punish, but a limit that fits perfectly with the justifications of punishment.

\section{KEY WORDS:}

Penal guarantees, punitive power, political power, principle of legality, psychological coercion. 


\section{INTRODUCCIÓN}

En ¿Qué es la filosofía?, una conferencia pronunciada en agosto de 1955 en Cerisy-la-Salle a modo de introducción sobre un coloquio sobre la esencia de la filosofía, Martin HeIDEGGER sostenía que solamente es posible plantear la pregunta ¿qué es la filosofía? si entablamos un diálogo con el pensamiento griego y no solamente por el objeto de la pregunta, sino también por el modo en que formulamos el interrogante. De la lectura que hace del Teeteto de Platón y de Metafísica de Aristóteles, a HeIdegger le interesa ubicar a la filosofía y al filosofar dentro de un particular estado de ánimo. Este estado de ánimo es el asombro, y si bien aquí no me interesa restituir todas las dimensiones abiertas por la presentación de HEIDEGGER, sí quisiera enfatizar que a la luz de la obra de DESCARTES, el estado de ánimo que en la modernidad retoma y resignifica la pregunta fundamental de la filosofía ya no es el asombro sino la duda (HEIDEGGER, 2004, ¿Qué es la filosofía? 56-62). De alguna manera, existe una íntima vinculación entre los estados de ánimo y el modo en que formulamos nuestros interrogantes.

Mis líneas de trabajo e investigación rara vez se relacionan con asuntos penales y me considero un simple lector aficionado, o más bien ocasional, de estas cuestiones. Como extranjero en esta temática, en general leo con asombro que buena parte de los escasos discursos jurídicos progresistas y hasta de izquierda se sitúen alrededor de los problemas penales. Dicho de otro modo, no es ninguna novedad que buena parte del discurso jurídico es conservador y que las conceptualizaciones progresistas y de izquierda son especialmente excepcionales. Sin embargo, no deja de asombrar que en la dimensión en la cual el derecho más se asemeja a la fuerza y la aplicación de dolor, y esa fuerza y 
ese dolor se direcciona hacia los cuerpos pobres, se encuentren las conceptualizaciones más progresistas y de izquierda. El interrogante es ¿cómo entender que en el ámbito del derecho penal, direccionado a la persecución y encierro de excluidos, se articulen discursos progresistas y de izquierda? ¿Cómo comprender esta paradoja? ¿Estamos realmente frente a una paradoja?

En el marco de estos discursos progresistas y hasta de izquierdas, las denominadas garantías del proceso penal, o más bien las garantías de quienes son o pueden ser eventualmente perseguidos por el sistema penal, ocupan un lugar predominante. Con algo de generalidad podría decirse que a excepción del denominado abolicionismo penal, las líneas más progresistas del derecho penal depositan en el sistema de garantías del liberalismo una extraordinaria confianza para atenuar las atrocidades del sistema penal. Uno podría pensar que efectivamente las garantías limitan cierto ejercicio del poder, pero también lo legitiman. De esta manera, la denostada ley del talión que predica "el ojo por ojo, diente por diente" podría ser leída en clave garantista puesto que en definitiva limita a solamente un ojo por cada ojo, y solamente un diente por cada diente. Ya en este registro, entonces, mi asombro sobre el discurso progresista y de izquierda en el terreno fangoso del derecho penal se transforma en una $d u d a$. En una $d u d a$ sobre aquellas variables, en especial las garantías liberales, sobre las cuales se deposita esa extraordinaria confianza para atenuar los excesos del sistema penal. De esta manera cabe preguntarse ¿qué valor tienen las garantías? ¿Qué relación existe entre ellas y el sistema penal? ¿Las dudas sobre las garantías pueden ser la clave para resolver el asombro que causa un discurso progresista y de izquierda en el ámbito penal? 
Aquí no abordaré todos mis interrogantes, y no creo que alcance atenuar mi asombro ni despejar todas mis dudas. Ni siquiera abordaré el discurso garantista en su totalidad, pero en mis indagaciones alrededor del principio de legalidad encontrarán como trasfondo estos mantos de asombro y dudas.

En primer lugar presentaré de modo genérico cómo el principio de legalidad se conceptualiza como un límite al poder punitivo, para luego abordar de modo más preciso la manera en la cual Eugenio Raúl ZaFFARONi y Luigi FERRAJOLI lo exhiben como un dique de contención del poder de castigar. Luego, tras subrayar que el principio de legalidad fue incluido en el sistema legal por las mismas agencias que tienen el poder de castigar, daré cuenta de los desarrollos de BECCARIA y Feuerbach y sostendré que en sus conceptualizaciones el principio de legalidad es un límite del poder de castigar, pero un límite que se ajusta perfectamente con la justificación del castigo. Por último ensayaré unas breves reflexiones finales.

\section{PRINCIPIO DE LEGALIDAD Y PODER PUNITIVO}

\section{NOTAS PRELIMINARES}

El principio de legalidad no es patrimonio del derecho penal, sino que también tiene su aplicación y funcionamiento en el derecho tributario y en el derecho administrativo. Sin embargo aquí quisiera detenerme en el modo en que se conceptualiza la relación entre el principio de legalidad y el poder punitivo. En términos generales se apunta al principio de legalidad como aquel que indica que "no hay crimen, no hay pena, sino hay ley previa," y en numerosas ocasiones se lo menciona mediante 
su formulación latina nullum crimen nulla poena sine lege praevia.

Una primera revisión sobre la literatura que aborda el principio de legalidad indica que se trata de un dispositivo para limitar, para establecer frenos y diques de contención, al poder punitivo del Estado. Y no se trata de una literatura marginal, de aproximaciones periféricas de la academia jurídica, sino que la propia Corte Interamericana de Derechos Humanos ha ligado estrechamente el principio de legalidad con la necesidad de contener al poder punitivo, puesto que en numerosos pronunciamientos sostuvo que "el principio de legalidad constituye uno de los elementos centrales de la persecución penal en una sociedad democrática" (Corte Interamericana de Derechos Humanos, 21/08/2013, "Caso Mémoli vs. Argentina, excepciones preliminares, fondo, reparaciones y costas; párr. 154; 23/11/2012, "Caso Mohamed vs. Argentina, excepción preliminar, fondo, reparaciones y costas," párr. 130; 06/05/2008, "Caso Yvon Neptune vs. Haití, fondo, reparaciones y costas" párr. 125; 20/06/2005, "Caso Fermín Ramírez vs. Guatemala, fondo, reparaciones y costas", párr. 90; 27/11/2013, “J. vs. Perú, excepción preliminar, fondo, reparaciones y costas," párr. 278). Además, subrayó que era especialmente importante en tanto que límite y regulación al poder punitivo: "en un Estado de Derecho, los principios de legalidad e irretroactividad presiden la actuación de todos los órganos del Estado, en sus respectivas competencias, particularmente cuando viene al caso el ejercicio de su poder punitivo" (Corte Interamericana de Derechos Humanos, 06/05/2008, "Caso Yvon Neptune vs. Haití, fondo, reparaciones y costas," párr. 125; 20/06/2005, "Caso Fermín Ramírez vs. Guatemala, fondo, reparaciones y costas," párr. 90; 31/08/2008, "Caso Ricardo Canese vs. Paraguay fondo, reparaciones y costas," párr. 177; 
18/11/2004 “Caso De La Cruz Flores vs. Perú, fondo, reparaciones y costas," párr. 80; 02/02/2001, "Caso Baena Ricardo y otros vs. Panamá, fondo, reparaciones y costas," párr. 107; 25/11/2005, “Caso García Asto y Ramírez Rojas vs. Perú, fondo, reparaciones y costas," párr. 187).

Esta conceptualización del principio de legalidad también se lee en diseños teóricos sofisticados, que no dudan en articularlo como un poderoso límite al poder de castigar. En lo que sigue me interesa presentar el modo en que el principio de legalidad se inscribe en los desarrollos conceptuales de los autores notablemente relevantes en buena parte de América Latina como son Eugenio Raúl ZafFARoni y Luigi FERrAJOLI. A mi modo de ver, presentar sus desarrollos es importante no solamente por la extraordinaria rigurosidad e influencia que tienen sus propuestas teóricas sino también porque son autores leídos por los sectores más progresistas del derecho penal.

\section{DERECHO Y JUSTICIA PENAL COMO LÍMITES AL PODER PUNITIVO. EL PRINCIPIO DE LEGALIDAD EN LA OBRA DE EUGENIO ZAFFARONI}

Tras constatar el fracaso de las teorías legitimantes del castigo, ZAFFARONI ensaya una teoría negativa y agnóstica de la pena, conceptualización que se construye justamente a la luz de este fracaso (Zaffaroni, Alagia, Slokar, 2002, Derecho Penal. Parte General 44). De esta manera puede afirmarse que "la pena es (a) una coerción, (b) que impone una privación de derechos o un dolor, (c) que no repara ni restituye y (d) ni tampoco detiene las lesiones en curso ni neutraliza los peligros inminentes" (Zaffaroni, Alagia, Slokar 44). El carácter negativo de esta conceptualización reside en que no asigna ninguna función 
positiva a la pena y en que se obtiene a través de una exclusión. Asimismo, es un abordaje "agnóstico en cuanto a su función, porque parte de su desconocimiento" (ZafFaroni, Alagia, SLOKAr 45). ${ }^{2}$

Es a partir de esta teoría negativa y agnóstica de la pena que ZAFFARONI entiende el rol de la judicatura, las garantías penales, y construye su teoría del delito (Zaffaroni, Alagia, Slokar). ${ }^{3}$ En todos los casos, la tarea de los jueces y del derecho penal es establecer límites a un desbocado poder punitivo, evitando que el Estado de derecho devenga en un Estado de policía. En este orden de ideas, "la función más obvia de los jueces penales y del derecho penal (como planeamiento de las decisiones de éstos), es la contención del poder punitivo. Sin la contención jurídica (judicial), el poder punitivo quedaría librado al puro impulso de las agencias ejecutivas y políticas y, por ende, desaparecería el estado de derecho y la República misma" (ZafFAroni, Alagia, SLOKAR 5).

En línea con lo anterior, respecto de las conceptualizaciones en materia penalZAFFARONI no duda en postularque toda construcción teórica debe elegir entre: "(a) legitimar discursivamente la criminalización y el ejercicio del poder punitivo por parte de todas

2 Además "el sentido metafórico de la expresión agnóstica sirve para poner de manifiesto la idolatría en que han caído las teorías legitimantes del poder punitivo, que sostienen su omnipotencia y lo convierten en un ídolo adorado por muchos fanáticos." (ZAFFARONI, 2005a, "Culpabilidad y vulnerabilidad social" 239).

3 De modo específico, en algunos trabajos ha abordado la culpabilidad y la prescripción desde la teoría agnóstica (ZAFFARONI, 2005a; ZAFFARONI, 2005b, "Notas sobre el fundamento de la imprescriptibilidad de los crímenes de lesa humanidad"). 
las agencias del sistema penal; o (b) limitar la legitimación al poder de reducción de sus agencias jurídicas (legitimar el acotamiento de la criminalización)" (Zaffaroni, Alagia, Slokar 29). Es claro que ZAFFARONI se inclina por la segunda de las opciones, pero para realizar esta elección antes es necesario haber decidido si “(a) en homenaje a la criminalización, se legitima la reducción del poder de las agencias jurídicas o si (b) en homenaje a la limitación de la criminalización, se legitima el aumento del poder de éstas" (Zaffaroni, Alagia, Slokar 29). De alguna manera, el dispositivo para (b) limitar la criminalización parece ser (b) el incremento y la legitimación del poder de las agencias judiciales. Es por ello que, respecto de los jueces penales, indica que "siempre que las agencias jurídicas deciden limitando y conteniendo las manifestaciones del poder propias del estado de policía, ejercen de modo óptimo su propio poder, están legitimadas, como función necesaria para la supervivencia del estado de derecho y como condición para su reafirmación contenedora del estado de policía que invariablemente éste encierra en su propio seno" (Zaffaroni, Alagia, Slokar 52). Finalmente, es a la luz de estas miradas sobre las teorizaciones en materia penal y el rol de la judicatura que propone refundar el derecho penal liberal "sobre la base de un agnosticismo completo acerca del poder punitivo, reconocido sólo como inevitable presencia política necesitada de contención, y la cuidadosa legitimación del ejercicio del poder jurídico penal como contención del poder punitivo" (ZAFFARONI, 2005c, "El derecho penal liberal y sus enemigos" 174).

Estas conceptualizaciones construidas alrededor de la teoría agnóstica y negativa de la pena y la consecuente urgencia de limitar el poder punitivo se mantienen, aunque con otras herramientas teóricas, en El enemigo en el derecho penal. Allí postula que históricamente el poder punitivo discriminó a los 
seres humanos y le dirigió un trato punitivo a quienes consideraba enemigos, y en la medida en que este tratamiento se efectuó con la autorización de la legislación, "la doctrina consecuente con el principio del estado de derecho debe tratar de limitar o reducir, o, al menos acotar, el fenómeno para que no desaparezca el estado de derecho" (ZAFFARONI, 2009, El enemigo en el derecho penal 12).

Teniendo en cuenta esta comprensión sobre el poder punitivo y la extrema necesidad de limitarlo y establecer un sistema de diques para que el Estado de derecho no se transforme en un Estado policial, ZAFFARONI menciona una serie de principios limitativos, que no se realizan de modo absoluto, sino que hay que leerlos como inacabados o de realización progresiva; y que no son un número cerrado sino que necesitan de una constante reactualización en función de las necesidades de contención del poder punitivo. Estos principios pueden agruparse de acuerdo a los que constituyen el conjunto de manifestaciones del principio de legalidad, los que excluyen toda punición incompatible con los derechos humanos, los que derivando del principio de estado de derecho o de la forma republicana de gobierno limitan la criminalización (ZafFaroni, Alagia, SloKar110-111).

Del principio de legalidad penal, que ZAFFARONI presenta como un "límite derivado de la función política" (ZAFFARoni, AlagiA, SLOKAR 107), se derivan los principios de:

a- legalidad formal, que indica que la única fuente de norma penal es la ley que respeta las formalidades previstas por la Constitución;

b- máxima taxatividad legal e interpretativa, que exige que la tipificación de los delitos se realice con la máxima precisión 
posible, al mismo tiempo que excluye toda analogía en la interpretación e impone que en caso de dudas se opte por aquella interpretación que reduzca la criminalización;

c- respeto histórico al ámbito legal de lo prohibido, que obliga a tomar en cuenta el contexto en el cual fue sancionada la ley y evitar una amplificación del tipo penal; ${ }^{4}$

d- irretroactividad de la ley penal, que impide que alguien sea penado por un hecho que al tiempo de cometerse no era delito, $\mathrm{o}$ que se le aplique una pena más gravosa que la entonces vigente (Zaffaroni, Alagia, Slokar 111-124).

Si bien la presentación de cada una de las dimensiones que derivan del principio de legalidad merecería un mayor tratamiento, y quizás también un análisis crítico, me interesa enfatizar sobre los siguientes aspectos conceptuales:

a) la misión del derecho penal y del poder judicial no es otro que poner límites a un poder punitivo que se encuentra amparado legalmente;

b) a la luz de esta misión contenedora de un desbocado e irracional poder punitivo hay que leer los límites instituidos por el principio de legalidad. Con otro andamiaje conceptual, y sin la articulación de una teoría agnóstica y negativa de la pena, estos dos elementos encuentran muchos aires de familia en la propuesta garantista de Luigi FERRAJOLI.

4 A partir de la contemplación del contexto en que fue sancionada la ley penal, de modo muy valioso ZAFFARONI sostuvo que el artículo 194 del código penal argentino no podría ser aplicado a las protestas sociales que tuvieran como repertorio al corte de ruta (ZAFFARONI, 2002, “El derecho penal y la protesta social”; 2010, “Derecho penal y protesta social"). 


\section{GARANTISMO, DERECHO PENAL MÍNIMO \\ Y LA LEY DEL MÁS DÉBIL}

\section{EL PRINCIPIO DE LEGALIDAD \\ EN LA OBRA DE LUIGI FERRAJOLI}

Si en la obra de ZAFFARONI se instituye como misión del derecho penal y de los jueces penales la de limitar el poder punitivo del Estado, en los desarrollos de Luigi FerRAJOLI esta labor de contención la cumple el denominado garantismo o derecho penal mínimo, que se configura como la ley del más débil. Es importante remarcar que el autor italiano desarrolló estas conceptualizaciones a lo largo de casi veinte años, período que se inicia con la publicación de Derecho y razón en 1989 y que culmina con Principia Iuris aparecido en 2007. Asimismo, son numerosos los artículos y conferencias que completan su enorme producción teórica. Si bien a lo largo de estos años es posible encontrar matices en sus desarrollos, y hay un tránsito desde el garantismo penal hacia la construcción de un paradigma del derecho y la democracia (CARBOnell, 2010, Luigi FerRAJOLI. "Teórico del derecho y de la democracia" 14), en mi presentación subrayaré las continuidades en su esfuerzo conceptual por limitar la potestad punitiva.

De acuerdo con FERRAJOLI, los principios garantistas funcionan como un esquema epistemológico de identificación de la desviación penal que aseguran, en comparación con otros modelos penales, "el máximo grado de racionalidad y de fiabilidad del juicio y, por tanto, de limitación de la potestad punitiva y de tutela de la persona contra la arbitrariedad" (FERRAJOLI, 1995, Derecho y razón 34). En términos generales, podemos presentar a las garantías penales y procesales como "esencialmente garantías 
negativas, dirigidas a limitar el poder punitivo en defensa de las libertades individuales" (Ferrajoli, 2010a, "Garantías" 67). Dicho de otro modo, las garantías son "técnicas dirigidas a minimizar la violencia y la potestad punitiva: es decir, a reducir en lo posible los delitos, la arbitrariedad de los jueces y la aflictividad de las penas" (FERRAJOLI, 2006a, "La pena en una sociedad democrática” 22).

Dentro de los elementos que constituyen al garantismo, podemos distinguir "uno relativo a la definición legislativa y el otro a la comprobación jurisdiccional de la desviación punible" (FERRAJOLI 1995 34). En este marco, el primero de los elementos que menciona FERRAJOLI es el convencionalismo legal tal y como resulta del principio de legalidad, principio que exige dos condiciones: "el carácter formal o legal del criterio de definición de la desviación y el carácter empírico o fáctico de las hipótesis de desviación legalmente definidas" (1995 34). La primera de las condiciones supone que para que pueda ser sancionada la desviación penal debe estar contemplada en una ley, y la segunda indica que la conceptualización de la desviación debe realizarse no en referencia a autores sino a actos. La primera de las condiciones se asemeja al principio de reserva de ley, según el cual el juez sólo puede calificar como delitos las conductas incluidas en las leyes, y la segunda agrega que el magistrado debe someterse a la ley sólo si la desviación incluida en ella cuenta con precisiones fácticas adecuadas. Teniendo en cuenta lo anterior, la primera condición puede conceptualizarse como principio de mera legalidad y "es una norma dirigida a los jueces, a quienes prescribe la aplicación de las leyes" (1995 35) y la segunda como principio de estricta legalidad "que es una norma dirigida al legislador, a quien prescribe la taxatividad y la 
precisión empírica de las formulaciones legales" (1995 36).$^{5}$ En términos más específicos, el principio de estricta legalidad opera como una "norma meta-legal que somete la validez de las leyes que autorizan el ejercicio de la violencia a una serie de requisitos que se corresponden con las garantías penales y procesales" (FERRAJOLI, 2010b, La legalidad violenta 176). Estas garantías que debe cumplir la ley para que el ejercicio de la violencia sea legítima son:

a) la tipicidad del uso de la fuerza que constituye la pena;

b) la taxatividad de los hechos delictivos, de los perjuicios que generan, y de la culpa del o los sujetos que intervienen;

c) que sea con un juez imparcial y mediante un proceso público contradictorio que se verifique la comisión del delito (FERRAJOLI 2010b 176). ${ }^{6}$

Teniendo en cuenta lo anterior, y ahora nuevamente en términos más generales, puede afirmarse que el garantismo alude a "un modelo teórico y normativo de derecho penal capaz de minimizar

5 La distinción entre principio de mera legalidad y de estricta legalidad atraviesa buena parte de la producción teórica de FERRAJOLI y se mantiene en Principia Iuris (FERRAJOLI, 2013a, Principia iuris Teoría del derecho y de la democracia. 1. Teoría del derecho 411-415).

6 En la línea de limitar el poder de castigar habría que sumar la denominada reserva de código, enunciada en sus trabajos más recientes. Ante un proceso de descodificación e inflación normativa en materia penal, FERRAJOLI propone reforzar el principio de legalidad y sustituir "la simple reserva de ley por una reserva de código, entendiendo por tal el principio, dotado de rango constitucional, de que en materia de delitos, penas y procesos penales no podrá introducirse ninguna norma si no es a través de la modificación o integración de los códigos penal o procesal, aprobada mediante un procedimiento legislativo agravado" (FERRAJOLI, 2013b, Principia iuris Teoría del derecho y de la democracia. 2. Teoría de la democracia derecho p. 376). 
la violencia de la intervención punitiva -tanto en la previsión legal de los delitos como en la comprobación judicial- sometiéndola a estrictos límites impuestos para tutelar los derechos de la persona" (FerRAJOLI 2010c, Garantías y derecho penal 193). Las garantías penales, dentro de las que se encuentra el principio de estricta legalidad se orientan a minimizar los delitos, es decir, "a reducir al máximo lo que el poder legislativo puede castigar" (Ferrajoli 2010c 193). Por su parte, las garantías procesales intentan minimizar los márgenes de arbitrariedad del poder judicial.

En varios de sus trabajos, FerRAJOLI asimila el garantismo al derecho penal mínimo y sostiene que éste alude a un paradigma meta-teórico de justificación del derecho penal, y a un paradigma teórico y normativo del derecho penal. En tanto paradigma metateórico, el derecho penal mínimo justifica el derecho penal sólo si puede alcanzar estos objetivos:

a) la minimización de las agresiones a bienes y derechos fundamentales;

b) la prevención y minimización de las penas arbitrarias.

En síntesis, justifica al derecho penal "si y sólo si es un instrumento de minimización de la violencia y del arbitrio que en su ausencia se producirían" (Ferrajoli, 2006b, "Crisis de legalidad y del derecho penal mínimo" 56). Por otra parte, en su dimensión teórica designa el sistema de garantías, tanto penales cuanto procesales, para satisfacer estos dos objetivos (FERRAJOLI 2006b 56; 2013b 348).

De acuerdo con un paradigma de derecho penal mínimo es necesaria la prevención de los ataques injustos pero también de las "penas informales o excesivas, es decir, de los castigos injustos" (FERRAJOLI 2013b 347). El primero de estos objetivos 
se logra a través de un sistema de restricciones formales que se realizan mediante normas penales estableciendo delitos y penas, mientras que el segundo de los objetivos se procura alcanzar "a través de las garantías penales y procesales [...] consistentes en límites impuestos a la potestad punitiva" (FerRAJOLI 2013b 347). Teniendo en cuenta estos dos objetivos que procura alcanzar el derecho penal mínimo, se entiende por qué también lo define como la ley del más débil contra la ley del más fuerte que estaría en vigor en su ausencia. Una ley que protege al sujeto más débil, que en el momento del delito es la parte ofendida, en la instancia del proceso es el imputado y durante la ejecución penal es el detenido (Ferrajoli 2006b 56; 2013b 348).

\section{PRINCIPIO DE LEGALIDAD, PODER PUNITIVO Y PODER POLÍTICO}

Tanto en los trabajos de ZaFfaroni cuanto en los de FerRajoli, aunque con diferentes formulaciones y niveles de exigencia, el principio de legalidad constituye un límite el poder punitivo. Con ciertos matices conceptuales, en ambos desarrollos teóricos una de las variables del principio de legalidad se articula como un límite al poder legislativo. Quizás con cierta reducción, pero me parece que es una reducción que se percibe fundamentalmente en los desarrollos de ZAFFARONI, puede afirmarse que la irracionalidad punitiva se ubica en los poderes ejecutivos y legislativos (Zaffaroni, Alagia, Slokar 5) y una muestra de ello es que la discriminación y tratamiento penal del enemigo funciona con amparo legal (ZAFFARONI 2009 11-12). De esta manera, al menos una de las dimensiones del garantismo en general y del principio de legalidad en particular, se articula como un límite del poder punitivo que se encuentra en las agencias ejecutivas y legislativas. Son varios los análisis críticos que se podrían realizar sobre esta 
formulación, así como también son muchos los reparos que tengo respecto de la confianza de las agencias judiciales, pero me interesa trabajar a partir de una sorpresa. O más bien de un asombro: ¿Cómo pensar que el principio de legalidad sea un límite a las agencias ejecutivas y legislativas, a las agencias políticas, si son éstas las que lo plasmaron constitucional y legalmente?

En una primera lectura, causa especial asombro que el discurso progresista y hasta de izquierda enuncie al principio de legalidad como un límite al poder punitivo, siendo que las instituciones que plasmaron el principio son exactamente las mismas que, de modo simultáneo, ejercieron y ejercen ese poder. A primera vista resulta asombroso que desde el propio poder punitivo emerja su limitación. O, dicho de otra manera, me genera ciertas dudas el potencial del principio de legalidad. Resignando algo de precisión conceptual, podríamos decir que el punto es el siguiente: dentro de la Asamblea Constituyente que en el artículo 8 de la Declaración de los derechos del hombre y del ciudadano del 26 de agosto de 1789 incluyó el principio de legalidad se encontraba el médico Joseph-Ignace Guillotin, quien propuso a esa misma Asamblea, y a la Legislativa, el uso de la guillotina.

Si tomamos el caso argentino -aunque creo que podrían tomarse muchos otros- fue este supuesto desbocado poder punitivo concentrado en las agencias políticas el que incluyó en el artículo 3 del Capítulo I de la Sección VII del Estatuto Provisional de 1815 que "el crimen es sólo la infracción de la Ley que está en entera observancia y vigor, pues sin este requisito debe reputarse sin fuerza." De la misma manera el artículo 13 del Capítulo III de la Sección Tercera del Reglamento Provisorio para la Dirección y Administración del Estado del 3 de diciembre de 1817, dictado por esas agencias legislativas y ejecutivas a las cuales hay que 
contener, disponía que "toda sentencia en causas criminales, para que se repute válida, debe ser pronunciada por el texto expreso de la ley."

Por su lado, fueron los propios actores políticos los que incluyeron en el artículo 18 de la Constitución sancionada en 1853 principio de legalidad, disponiendo que "ningún habitante de la Nación puede ser penado sin juicio previo fundado en ley anterior al hecho del proceso." Asimismo, en la década de 1880 las agencias administrativas y legislativas pusieron en práctica nuevos dispositivos del poder punitivo, sancionando en 1886 un código penal y en 1888 un código de procedimientos en lo criminal. La ley 2372, mediante la cual se sancionó el código de procedimientos, tuvo su origen en un proyecto presentado por el Poder Ejecutivo Nacional, logró media sanción en la Cámara de Diputados el veinticuatro de agosto de 1888, fue aprobado Cámara de Senadores el diez de septiembre de ese año, y entró en vigencia el primero de enero de 1889. La agencia ejecutiva y la legislativa, a los ojos de FERRAJOLI pero fundamentalmente de ZAFFARONI artífices por antonomasia del poder punitivo, incluyeron no escondido en alguna de sus disposiciones sino en el primer artículo el principio de legalidad, disponiendo que "ningún juicio criminal podrá ser iniciado sino por actos $\mathrm{u}$ omisiones calificados de delitos por una ley anterior, ni ser proseguido y terminado ante otros jueces que los ordinarios."7

7 El código de 1888 fue reformado en varias oportunidades y finalmente derogado en 1991 cuando entró en vigencia el Código Procesal de la Nación (ley 23.984), que también incluye en el artículo primero el principio de legalidad. 
Este pequeño desarrollo no implica poner en $d u d a$ que las agencias legislativas y ejecutivas sean responsables del funcionamiento del poder punitivo del Estado. Más bien, supone trazar mantos de $d u d a$ respecto de los alcances del principio de legalidad. Si tenemos en cuenta que fueron las propias agencias ejecutivas y legislativas las que lo incluyeron en textos constitucionales y legales, causa cierto asombro leer que el de legalidad sea un extraordinario principio para limitarlas.

Para aclarar algo de este oscuro panorama sería interesante dar con la racionalidad que explicó la inclusión del principio de legalidad en la Constitución y en el Código de Procedimientos en lo Criminal en Argentina. Sin embargo, como no es posible contar con esta información, ${ }^{8}$ creo que vale la pena analizar cómo éste se inscribe en los desarrollos conceptuales de Cesare Bonesa -Marqués de BECCARIA- y de Paul Johann Anselm Ritter von FEUERBACH, que de acuerdo a la literatura penal fueron los grandes formuladores del principio de legalidad. De acuerdo con esta literatura, en De los delitos y de las penas podemos encontrar los rasgos centrales del principio, que luego fue explícitamente formulado por el autor prusiano. Lo que me interesa, entonces,

8 En las actas de la Asamblea Constituyente de 1853 consta que el artículo 18 de la Constitución argentina se aprobó por unanimidad, y si existió algún tipo de debate o justificación no ha quedado documentado (Actas de las Sesiones Públicas del Soberano Congreso General Constituyente de la Confederación Argentina, 1939, 515) Por su lado, en el Diario de Sesiones de la Cámara de Diputados -10 de septiembre de 1888- y de Senadores -4 de octubre de 1888- no se registran debates y justificaciones sobre el Código de Procedimientos en lo Criminal, por lo que no es posible desentrañar la racionalidad que marcó la inclusión del principio de legalidad (Congreso Nacional- Cámara de Diputados, Diario de Sesiones 1888 631-659; Congreso Nacional- Cámara de Senadores, Diario de Sesiones, 1888 653-655). 
es rastrear cómo se inscribe el principio de legalidad en la fundamentación del castigo que se encuentra en las obras de Beccaria y de Feuerbach. A modo de simple adelanto, y en contraste con las propuestas de ZafFaroni y de Ferrajoli, es asombroso leer que para BECCARIA y FEUERBACH el principio de legalidad se inscribe dentro de sus fundamentaciones del castigo más que como límites ajenos al poder punitivo.

\section{LA LEY PENAL COMO LIBRO PÚBLICO Y SOLEMNE DE LOS DELITOS Y DE LAS PENAS}

Cesare Bonesa, Marqués de BECCARIA, nació en 1738 en Milán, ciudad en la que murió en 1774. Se graduó en la carrera de Derecho de la Universidad de Pavia, pero luego de la publicación De los delitos y las penas su desarrollo intelectual y profesional se situó en el ámbito de la economía, primero como profesor de "Economía política y comercio" de la Escuela Palatina, y luego como funcionario del Consejo Económico Supremo de Milán, donde trabajó desde 1771 hasta su muerte.

De los delitos y de las penas fue escrito entre 1763 y 1764 y el doce de abril de 1764 fue remitido a Livorno por correo y publicado por el editor Coltellini, al cuidado de Giuseppe Aubert (Pisani, "Cesare Beccaria y el Index Librorum Prohibitorum" 163). BECCARIA tenía veinticinco años, escribió buena parte de la obra en el Palazzo Verri, y prefirió que la publicación fuera anónima. ${ }^{9}$ El trabajo se compuso en el marco de la Accademia

9 En una carta que le escribió al Abate y Enciclopedista Morellet en mayo de 1776 justificaba el carácter anónimo de la publicación en estos términos: "cuando escribí esta obra tenía a la vista los ejemplos de Maquiavelo, de Galileo y de Giannone. He oído el ruido de las cadenas que sacude la superstición, y los gritos del fanatismo que 
dei Pugni, un círculo de intelectuales de Milán que tenía un periódico de difusión, Il Caffé, que se editó entre junio de 1764 y junio de 1766 y donde BeCCARIa publicó siete artículos, aunque ninguno sobre temas penales (GARCíA RAMírEZ, 2000, "Estudio introductorio. Beccaria: el hombre, la circunstancia, la obra" 14-15). De los delitos y de las penas fue rápidamente leído en los círculos intelectuales, gubernamentales y religiosos, y el propio Voltaire le realizó un comentario en el que, a propósito de la crítica a los suplicios, decía "el humano autor de los Delitos y de las Penas, tiene demasiada razón en quejarse de que el castigo es muy a menudo superior al crimen, y no rara vez pernicioso para el Estado, cuyo bien debe de ser su único objeto" (Voltaire, 1993, "Comentario sobre el libro de los delitos y de las penas" 170-171). Sin embargo su recepción no fue satisfactoria en todos los ámbitos, y es por ello que ya en agosto de 1764 la obra fue prohibida por los Inquisidores del Estado de la República Veneciana y en 1786 se incluyó en la lista general del Index librorum prohibitorum (GARCíA RAMÍREZ 18. Piani 137-143). Luego de esta primera edición de 1764, Beccaria fue introduciendo pequeñas modificaciones y la última edición revisada por BECCARIA fue la quinta, en la que incluyó una nueva advertencia -"Al lector"-, una "Introducción" y dos nuevos capítulos -"Del físico" y "Del perdón”-. ${ }^{10}$

ocultan los gemidos de la verdad. La vista de estos espectáculos horrorosos me ha determinado a envolver la luz algunas veces en nubes algo oscuras. He querido defender la humanidad sin ser su mártir" (BECCARIA, 1993, "Extracto de la correspondencia de Beccaria y de Morellet" 230).

Aquí trabajaré con una traducción de la quinta edición, que es una de las que posee más circulación puesto se trata de la publicada en Madrid en 1774 por Juan ANTONIO DE LAS CASAS, que además de ser la primera durante mucho tiempo fue la única disponible. 
Sería un anacronismo buscar en la obra de BECCARIA un propósito de limitar y atenuar el poder punitivo, básicamente porque la conceptualización de "poder punitivo" era ajena a la época. Sin embargo llama la atención que en la advertencia de la obra, se encarga de esclarecer que el objetivo de la obra no es disminuir la autoridad política sino incrementarla: "cualquiera que quisiera honrarme con su crítica, empiece por conocer bien el fin al que se dirige esta obra; fin que, conseguido, bien lejos de disminuir la legítima autoridad, servirá para aumentarla, si puede en los hombres más la razón que la fuerza, y si la dulzura y la humanidad la justifican a los ojos de todos" (BECCARIA, 2015, Tratado de los delitos y de las penas 13) No creo que sea posible asimilar lo que hoy denominamos "poder punitivo" con lo que dos siglos y medio atrás BECCARIA llamaba "legítima autoridad", pero para marcar un contraste con las lecturas contemporáneas llama la atención que el milanés no dude en aclarar que su obra no pretende disminuir la autoridad sino más bien incrementarla.

De acuerdo con la propuesta contractualista, para salir del estado de guerra los hombres sacrifican parte de su libertad, constituyen la soberanía, y el soberano se instituye como administrador de esa libertad. De todas maneras, para BECCARIA no basta constituir este depósito sino que es "necesario también defenderlo de las usurpaciones privadas de cada hombre en particular" (2005 19). Para evitar estas usurpaciones se vuelve necesario articular "motivos sensibles" para desincentivar el ánimo despótico de los individuos y "estos motivos sensibles son las penas establecidas contra los infractores de aquellas leyes" (2005 19). Si tenemos en claro lo anterior será fácil advertir "el fundamento del derecho soberano a penar los delitos: la necesidad de defender el depósito de la salud pública de las particulares usurpaciones" (2005 20). Fue por necesidad que los individuos cedieron una parte de sus 
libertades para constituir el depósito público de libertades, y "el agregado de todas esas pequeñas porciones de libertad posible forman el derecho de castigar: todo lo demás es abuso y no justicia" (2005 20). Como se observa con nitidez, el agregado de libertades funciona como límite del derecho de castigar, pero de modo simultáneo como legitimación de ese derecho. ${ }^{11}$

Si quisiéramos sintetizar los aportes conceptuales de BECCARIA podríamos sostener que: a) lo que funda el derecho de castigar es la necesidad de prevenir los delitos, y las penas son eficaces para tal cometido puesto que el placer y el dolor son los móviles de la acción humana; b) la amenaza de castigo es útil dado que se supone la imagen de un hombre racional -un homo oeconomicusque decide libremente la ejecución de los delitos, y lo hace a través de una razón calculadora que estudia costos y beneficios; c) la aplicación de la pena debe realizarse con celeridad y sin demoras, para establecer en el plano simbólico una asociación directa entre delito y castigo (Cid Moliné, LARrauri Pijoan, 2001, Teorías criminológicas 34-37). De esta manera, en la obra de BECCARIA no hay nada ningún interés en construir la ley del más débil ni nada que se asemeje a una teoría negativa y agnóstica de la pena, sino que hay esfuerzos por fundamentarla. No obstante, lo más interesante es que quien legitima el "derecho de castigar" también enuncia los trazos generales del principio de legalidad.

11 De esta manera, BARATTA afirma que "el contrato social está en la base de la autoridad del Estado y de las leyes; su función, que se deriva de la necesidad de defender la coexistencia de los intereses individualizados en el Estado civil, constituye también el límite lógico de todo legítimo sacrificio de la libertad individual mediante la acción del Estado, y en particular del ejercicio de la potestad punitiva del Estado mismo" (BARATTA, 2004, Criminología crítica y crítica del derecho penal 26). 
BECCARIA afirma que "sólo las leyes pueden decretar las penas de los delitos, y esta autoridad debe residir únicamente en el legislador" (2015 21). Esta autoridad es propia del legislador y no del magistrado porque es aquél y no éste quien representa a los individuos unidos en el contrato social y por ello "ningún magistrado bajo pretexto de celo o de bien público puede aumentar la pena establecida" (2015 21). Es interesante que esta formulación similar al principio de legalidad se instituye como una limitación no hacia las agencias ejecutivas y legislativas -distinción no tan nítida en el siglo XVIII- sino hacia los magistrados. ${ }^{12}$

De todas maneras aquello que resulta más destacable es que la necesidad de establecer las leyes por escrito, aplicables sólo si son anteriores a la consumación del delito, se inscribe dentro de la racionalidad del castigo que propone BECCARIA. Uno de los grandes problemas que encuentra el milanés es la oscuridad de las leyes, su escritura en una lengua extraña para el pueblo: "en una lengua que forma de un libro público y solemne uno casi privado y doméstico" (2015 24). Es importante que las leyes puedan leerse como un libro de educación cívica ya que "cuanto mayor fuere el número de los que entendieren y tuvieren entre las manos el código sagrado de las leyes, tanto menos frecuentes serán los delitos" (2015 24). Que las penas se encuentren en las leyes, y

12 En vistas de limitar la actuación de los magistrados, BECCARIA les negaba la facultad de interpretar las normas penales y acotaba su labor a la constitución de un silogismo: "la mayor debe ser la ley general, la menor la acción conforme o no a la ley, la consecuencia la libertad o la pena. Cuando el juez por fuerza o voluntad quiere hacer más de un silogismo, se abre la puerta a la incertidumbre" (2015 22). Es así que "donde las leyes son claras y precisas, el oficio del juez no consiste más que en comprobar un hecho" (2015 36). 
que ellas sean claras y precisas -elementos característicos del principio de legalidad-, se vincula estrechamente con el objetivo del castigo. El fin de la pena no es atormentar a los individuos ni tampoco deshacer un delito ya cometido sino "impedir al reo causar nuevos daños a sus ciudadanos y retraer a los demás de la comisión de otros iguales" (2015 34). Es fundamental, entonces, que las penas estén estipuladas en leyes de fácil acceso porque "no hay duda de que la ignorancia y la incertidumbre de las penas ayudan la elocuencia de las pasiones" (2015 24).

Esta inscripción del principio de legalidad dentro de la propia racionalidad del castigo, se reitera en las críticas que BECCARIA realiza sobre las penas crueles. Su reproche no es ajeno a su propuesta punitiva, puesto que la limitación de las penas crueles se asienta en la racionalidad que guía el sistema penal: desincentivar la comisión de delitos. Es así que "no es la crueldad de las penas uno de los más grandes frenos de los delitos, sino la infalibilidad de ellas" (2015 55). Al contrario de establecer penas atroces, "la certidumbre del castigo, aunque moderado, hará siempre mayor impresión que el temor de otro más terrible, unido con la esperanza de la impunidad" (2015 55). La representación de las desventajas de las penas tiene que estar más presente que las consecuencias placenteras de los delitos (FoucAult, 1975, Surveiller et punir 108), y para que la pena logre este efecto "basta que el mal de ella exceda al bien que nace del delito, y en este exceso de mal debe ser calculada la infalibilidad de la pena y la pérdida del bien que el delito produciría. Todo lo demás es superfluo y, por tanto, tiránico" (BECCARIA, 2015 55).

De los delitos y de las penas no incluye una formulación tan precisa del principio de legalidad, pero sí enuncia explícitamente que los delitos tienen que estar plasmados en las leyes y que 
los jueces no deben aplicar penas distintas a las sancionadas legalmente. Lo notable es que estos rasgos del principio de legalidad no son un dique al modo en que BECCARIA justificaba el castigo, sino que estos rasgos se insertan en esta justificación. Será FEUERBACH quien brinde carta de ciudadanía al principio de legalidad, pero al igual que el milanés, lo inscribirá dentro de la racionalidad del castigo.

\section{COACCIÓN PSICOLÓGICA Y PRINCIPIO DE LEGALIDAD EN LA OBRA DE FEUERBACH}

Paul Johann Anselm Ritter von Feuerbach nació el 14 de noviembre de 1775 y sus primeras publicaciones datan del decenio de 1790: en 1794 apareció Sobre el estado de naturaleza, y en 1795 Ensayo sobre el concepto del derecho y Sobre la imposibilidad de un primer principio absoluto de la filosofía. También en 1795 publicó su primer libro, titulado Sobre la única demostración posible acerca de la existencia y validez de los derechos naturales, y obtuvo el título de doctor en filosofía en la Universidad de Jena, en la que en 1799 logró el doctorado en derecho. Por esos años también publicó Crítica del derecho natural como propedeútica para una ciencia del derecho natural en 1796, Anti-Hobbes. O sobre los límites del poder supremo y el derecho de coacción del ciudadano contra el Estado en 1797, Revisión de los principios y conceptos fundamentales del derecho penal positivo en 1799 y el Tratado del derecho penal común vigente en Alemania en 1801. Durante este período pasó por las Universidades de Jena, Kiel y Landshut. En 1805 se radicó en Münich y en el marco del Ministerio de Justicia comenzó a trabajar en varios proyectos legislativos, dentro de los cuales se destaca el Código Penal bávaro, que entró en vigencia el primero de octubre de 1813. A partir del año se desempeñó como juez en 
Bamberg y Ansbach, cargo que ocupó hasta su muerte el 29 de mayo de 1833.

La célebre formulación del principio de legalidad se lee en el Tratado del derecho penal común vigente en Alemania, donde también se incluye una justificación y legitimación del Estado y del castigo. De acuerdo con Feuerbach, el Estado es "una sociedad civil organizada constitucionalmente mediante el sometimiento a una voluntad común" (Feuerbach, 1989, Tratado de derecho penal común vigente en Alemania 58) y su objetivo es lograr "la condición jurídica, es decir, la existencia conjunta de los hombres conforme a las leyes del derecho" (1989 58). Toda lesión jurídica contradice el objetivo del Estado y es por ello que éste "tiene el derecho y el deber de hallar institutos mediante los cuales se impidan las lesiones jurídicas" (1989 59). El Estado debe acudir a la coerción física para cancelar las lesiones jurídicas:

a. sea con anterioridad, impidiendo las lesiones;

b. sea con posterioridad, obligando a reparar el daño.

Sin embargo "la coerción física es insuficiente para impedir a las lesiones jurídicas" (1989 59) ya que para proteger derechos cuyo daño es irreparable hay que conocer previamente la eventual lesión, algo que no es posible. Es por ello que si se quieren impedir las lesiones jurídicas "deberá existir otra coerción junto con la física, que se anticipe a la consumación de la lesión jurídica y que, proviniendo del Estado, sea eficaz en cada caso particular, sin que requiera el previo conocimiento de la lesión" (1989 60). Para prevenir la lesión jurídica sin la necesidad de conocer fehacientemente si se producirá, FEUERBACH recomienda apelar a una coacción que para lograr tal cometido "sólo puede ser de índole psicológica” (1989 60). 
En línea con lo anterior, FEUERBACH desarrolla una propuesta de coacción psicológica. A su modo de ver, toda lesión jurídica tiene una causa psicológica en la sensualidad, en un impulso placentero a cometer una contravención. De todas maneras este "impulso sensual puede ser cancelado a condición de que cada uno sepa que a su hecho ha de seguir, ineludiblemente, un mal que será mayor que el disgusto emergente de la satisfacción de su impulso al hecho" (1989 60). ${ }^{13}$ La amenaza y la aplicación de un mal que se encuentra en la ley de un Estado lleva el nombre de pena civil, y aquello que la fundamenta es la "necesidad de preservar la libertad recíproca de todos mediante la cancelación del impulso sensual dirigido a las lesiones jurídicas" (1989 61). De esta manera, pueden desagregarse las siguientes finalidades tanto de la amenaza de una pena en la ley cuanto de su efectiva aplicación:

“I) El objetivo de la conminación de la pena en la ley es la intimidación de todos, como posibles protagonistas de lesiones jurídicas;

II) El objetivo de su aplicación es dar fundamento efectivo a la conminación legal, dado que sin la aplicación la conminación quedaría hueca" (1989 61).

El fundamento jurídico de la aplicación de la pena es la previa amenaza legal, y relacionando los distintos aspectos conceptuales desarrollados puede afirmarse que "toda pena jurídica dentro del

13 Tal como FOUCAULT subraya al momento de describir el penalismo ilustrado, el castigo debe cumplir con la regla de la idealidad suficiente, que indica que si la motivación del delito radica en las ventajas que se obtienen a partir de su comisión, la eficacia de la pena depende de la desventaja que se sufre luego de cometer el delito. La efectividad reside no en la aplicación de la pena en el cuerpo sino en la representación de las desventajas del castigo (97). 
Estado es la consecuencia jurídica, fundada en la necesidad de preservar los derechos externos, de una lesión jurídica y de una ley que conmine un mal sensible" (1989 63).

La propuesta de justificación y fundamentación de la pena desarrollada por FEUERBACH puede sintetizarse teniendo en cuenta estos argumentos secuenciales:

1. el Estado, como sociedad civil organizada, debe impedir las lesiones jurídicas;

2. como no se pueden evitar acudiendo únicamente a la coerción física, hay que apelar a la coerción psicológica;

3. la coerción psicológica se logra incluyendo amenazas de penas en las leyes, y luego aplicando esas penas ante las lesiones jurídicas efectivamente cometidas. Sin embargo, lo interesante es que el afamado principio de legalidad no se articula como un límite externo al funcionamiento del castigo, sino que se inserta en la justificación de su teoría psicológica de la pena. Es así que luego de brindar su conceptualización de pena jurídica subraya que "de ahí surgen, sin excepción alguna, los siguientes principios derivados:

I) Toda imposición de pena presupone una ley penal (nulla poena sine lege). Por ende, sólo la conminación del mal por la ley es lo que fundamenta el concepto y la posibilidad jurídica de una pena. II) La imposición de una pena está condicionada por la existencia de la acción conminada (nulla poena sine crimine). Por ende, es mediante la ley como se vincula la pena al hecho, como presupuesto jurídicamente necesario.

III) El hecho legalmente determinado (presupuesto legal) está condicionado por la pena legal (nullum crimen sine poena legali). Consecuentemente, el mal, como consecuencia jurídica necesaria, se vinculará mediante la ley a una lesión jurídica determinada" (1989 63). 
No solamente es patente que el principio de legalidad se ajusta perfectamente a la propuesta de una coacción psicológica y que poco se asemeja tanto a un principio que limita un poder punitivo desbocado cuanto a una ley que busca la protección del más débil, sino que es notable que en el Anti-Hobbes FEUERBACH no menciona al afamado principio de legalidad. En una labor especialmente dedicada a dar cuenta de los límites del poder del soberano, el principio no solamente no es desarrollado sino que ni siquiera es nombrado.

En la primera línea del prefacio del Anti-Hobbes se lee que el trabajo "se ocupa de la solución a una de las cuestiones más importantes y también más difíciles del derecho público general" (FEuerbach, 2010, Anti-Hobbes o sobre los límites del poder supremo y el derecho de coacción del ciudadano contra el soberano 57). El libro tiene a Thomas HoBBES como el principal adversario "puesto que como jurista es el defensor más agudo y consecuente del despotismo y de la obediencia civil" (FEUERBACH 2010 60). En términos más conceptuales la pregunta que atraviesa el texto reza: "¿es verdad que la justicia impone una obediencia incondicional de los súbditos y un poder del soberano por encima de toda acción?" (2010 64). Dicho de otra manera, y en un registro bastante genérico, el objeto de estudio es "el soberano que ofende a su pueblo, y el pueblo que se protege contra esta injuria" (2010 85).

Ante esta pregunta, FEuerbach defiende la tesis según la cual "ni la persona del soberano está por encima de toda coacción, ni tampoco la nación tiene el deber de obediencia incondicional" (2010 99). A diferencia de HobBes -y también en parte de Immanuel KANT (1993 40)- FEUERBACH propone mostrar que frente al soberano $-\mathrm{O}$ regente como lo denomina- se justifica 
la resistencia "mediante coacción, cuando viola los contratos civiles básicos" (2010 181). Para justificar la resistencia, FEUERBACH desarrolla una serie de argumentos escalonados que permiten sostener que: a) con el pacto de sometimiento que se articula entre súbditos y soberano, éste "pone a su cargo plenos deberes" (2010 103). El pacto de sometimiento es un contrato bilateral que funda para ambas partes derechos y obligaciones, siendo que "el soberano promete gobernar al estado conforme a la voluntad general; los súbditos prometen obedecer sus leyes y disposiciones" (2010 103). El soberano está limitado por este pacto de sometimiento sin necesidad de una declaración expresa, puesto que el pueblo no puede -de modo simultáneo y sin caer en contradicción- querer y no querer que se cumplan los estándares del pacto (2010 111); b) si el soberano actúa contrariando los deberes del pacto se transforma en una persona privada, por lo que "no será presionado el soberano sino una persona privada si el pueblo -a causa de esta lesión- se levanta en su contra" (2010 $103)$; c) el deber de obediencia del pueblo no es absoluto puesto que sólo se mantiene mientras el soberano no actúe violando el pacto de sometimiento. Además, la promesa de obediencia absoluta llega a disparates y contradicciones tales como que los súbditos eligen a un soberano para que exista el Estado, pero deben obedecerlo si el soberano pretende disolver ese mismo Estado, o deben considerar como cuadrado a un círculo si así lo dispone el soberano (2010 121-122). Es por ello que "el contrato civil debe reconocer los límites que le ha indicado la voluntad general, o bien renunciar a ese título de honor" (2010 123).

$\mathrm{Si}$ bien son interesantes, no deseo profundizar sobre estos desarrollos de Feuerbach en Anti-Hobbes, pero sí me interesa remarcar que siendo un texto especialmente dedicado a postular la existencia de límites al soberano, en ningún momento 
aludió al principio de legalidad. Incluso ensaya una extensa conceptualización del derecho penal (2010 143-147), se reitera la fundamentación psicológica de la coacción y la importancia de la amenaza para cancelar las razones de los deseos antijurídicos (2010 148-150), pero en ningún pasaje el principio de legalidad aparece en tanto que límite al soberano ni a su poder de castigar.

\section{NOTAS FINALES}

Creo que en estas líneas, por cierto muy breves y que deben leerse como simples reflexiones preliminares, no he despejado por completo mis dudas. En un campo tan conservador como el jurídico, no deja de asombrar que los escasos discursos progresistas y de izquierda se encuentren en el ámbito penal, el más estrechamente vinculado con la persecución y aplicación de dolor sobre los cuerpos pobres. Ante este panorama, no es tan difícil convertir aquel asombro en dudas. No en dudas sobre la dureza y crudeza del sistema penal sino respecto de ese discurso progresista o de izquierda.

Dentro las conceptualizaciones progresistas o de izquierda, los valiosos desarrollos de Eugenio Raúl ZAFFARONi y Luigi FERRAJOLI ocupan un papel muy importante en la academia y en la judicatura, y por ello me ha interesado indagar sobre sus núcleos teóricos. En términos generales, aunque con más intensidad en las conceptualizaciones del argentino, me ha causado asombro que los principios liberales, o más bien uno de ellos como el de legalidad, que se proponían como límites al poder punitivo y a las agencias políticas y ejecutivas, fueron principios plasmados jurídicamente por estas agencias. Este asombro devino en una serie de dudas sobre el principio de legalidad, dudas que 
quizás podrían precipitarse sobre otros principios, garantías o limitaciones. No tanto porque sospeche o dude del potencial limitador del principio de legalidad, o de otras garantías, sino porque la lectura de quienes diseñaron el principio enseña que esa limitación se inscribe perfectamente en los fundamentos, objetivos y racionalidades que tiene el castigo. En definitiva, creo que a la luz de las dudas sobre los límites puede despejarse el asombro que causa que las agencias punitivas sancionen sus propios límites. Quizás, aunque tengo dudas, esos límites sean para castigar más y mejor. 


\section{BIBLIOGRAFÍA}

ACTAS de las sesiones públicas del soberano congreso general constituyente de la confederación argentina, años 18521854. Asambleas Constituyentes Argentinas 18131898, Emilio Ravignani Ed. Buenos Aires: Instituto de Investigaciones Históricas de la Facultad de Filosofía de la Universidad de Buenos Aires, 1939. 403-538.

BARATTA, Alessandro. Criminología crítica y crítica del derecho penal. Introducción a la sociología jurídico penal. Buenos Aires: Siglo XXI, 2004.

BECCARIA, Marqués de. "Extracto de la correspondencia de Beccaria y de Morellet", en Tratado de los delitos y de las penas, Buenos Aires, Heliasta, 1993.

, Tratado de los delitos y de las penas. Madrid: Universidad Carlos III de Madrid, 2015

CARBOnell, Miguel. "Luigi Ferrajoli. Teórico del derecho y de la democracia." Democracia y garantismo, Luigi Ferrajoli. Madrid: Trotta, 2010. 13-22.

CID Moliné, José, Larrauri Pijoan, Elena. Teorías criminológicas. Explicación y prevención de la delincuencia. Barcelona: Bosch, 2001.

Congreso nACIOnAL- Cámara de Diputados. Diario de Sesiones, 46 ${ }^{\text {a }}$ Sesión ordinaria del 10 de septiembre de 1888. 
CONGRESO NACIONAL- Cámara de Senadores. Diario de Sesiones, 2 Sesión de Prórroga- Octubre 4 de 1888.

CORTE Interamericana de Derechos Humanos, "Caso Baena Ricardo y otros vs. Panamá,fondo, reparaciones y costas." 02/02/2001, http://www.corteidh.or.cr/docs/casos/ articulos/Seriec_72_esp.pdf [Consulta: 02/07/2016].

"Caso De La Cruz Flores vs. Perú, fondo, reparaciones y costas." 18/11/2004,http://www.corteidh.or.cr/docs/casos/ articulos/seriec_115_esp.pdf [Consulta: 02/07/2016].

"Caso Fermín Ramírez vs. Guatemala, fondo, reparaciones y costas." 20/06/2005, http://www.corteidh.or.cr/docs/casos/articulos/ seriec_126_esp.pdf [Consulta: 02/07/2016].

“Caso García Asto y Ramírez Rojas vs. Perú, fondo, reparaciones y costas." 25/11/2005, http://www.corteidh.or.cr/docs/casos/ articulos/seriec_137_esp.pdf [Consulta: 02/07/2016].

"Caso Yvon Neptune vs. Haití, fondo, reparaciones y costas." 06/05/2008, http://www.corteidh.or.cr/docs/casos/ articulos/seriec_180_esp1.pdf [Consulta: 02/07/2016].

"Caso Ricardo Canese vs. Paraguay fondo, reparaciones y costas." 31/08/2008, http://www.corteidh.or.cr/docs/casos/ articulos/seriec_111_esp.pdf [Consulta: 02/07/2016].

"Caso Mohamed vs. Argentina, excepción preliminar, fondo, reparaciones y costas." 23/11/2012, http://www.corteidh. or.cr/docs/casos/articulos/seriec_255_esp.pdf [Consulta: 02/07/2016]. 
"Caso Mémoli vs. Argentina, excepciones preliminares, fondo, reparaciones y costas." 21/08/2013, [Consulta: 02/07/2016].

“Caso J. vs. Perú, excepción preliminar, fondo, reparaciones y costas." http://www.corteidh.or.cr/docs/casos/articulos/ seriec_265_esp.pdf 27/11/2013, [Consulta: 02/07/2016].

FERRAJOLI, Luigi. Derecho y razón. Teoría del Garantismo penal. Madrid: Trotta, 1995.

, "La pena en una sociedad democrática." Garantismo penal. México DF: Universidad Autónoma de México, 2006a. 20-33.

,"Crisis de la legalidad y del derecho penal mínimo." Garantismo penal. México DF: Universidad Autónoma de México, 2006b. 55-68.

"Garantías." Democracia y garantismo. Madrid: Trotta, 2010a. 60-76.

, "La legalidad violenta." Democracia y garantismo. Madrid: Trotta, 2010b. 175-191.

, “Garantías y derecho penal." Democracia y garantismo. Madrid: Trotta, 2010c. 192-207.

, Principia iuris Teoría del derecho y de la democracia.

1. Teoría del derecho. Madrid: Trotta, 2013a.

, Principia iuris Teoría del derecho y de la democracia. 2. Teoría de la democracia derecho. Madrid: Trotta, 2013b. 
FEUERBACH, Paul Johann Anselm Ritter von, Tratado de derecho penal común vigente en Alemania. Buenos Aires: Hammurabi, 1989.

, Anti-Hobbes o sobre los límites del poder supremo $y$ el derecho de coacción del ciudadano contra el soberano. Buenos Aires: Hammurabi, 2010.

FOUCAULT, Michel. Surveiller et punir. Naissance de la prison. Paris: Gallimard, 1975.

GARCÍA Ramírez, Sergio. "Estudio introductorio. Beccaria: el hombre, la circunstancia, la obra." De los delitos y de las pena, Marqués de Beccaria. México DF: Fondo de Cultura Económica, 2000, 7-97.

HeIDEGGER, Martin. ¿Qué es la filosofía? Barcelona: Herder, 2004.

KANT, Immanuel. "En torno al tópico: «Tal vez eso sea correcto en teoría, pero no sirve para la práctica»." Teoría y praxis, Madrid: Tecnos, 1993. 25-40.

PISANI, Mario. "Cesare Beccaria y el Index Librorum Prohibitorum.” Eguzkilore 25 (2011): 135-145

VOLTAIRE. "Comentario sobre el libro de los delitos y de las penas." Tratado de los delitos y de las penas, Marqués de Beccaria. Buenos Aires: Heliasta, 1993. 169-212.

ZAFFARONI, Eugenio Raúl. "El derecho penal y la protesta social." Revista Jurisprudencia Argentina IV (2002): 384-392. 
, "Culpabilidad y vulnerabilidad social." En torno a la cuestión penal. Buenos Aires: Euros Editores, 2005a. 229-251.

, "Notas sobre el fundamento de la imprescriptibilidad de los crímenes de lesa humanidad." En torno a la cuestión penal. Buenos Aires: Euros Editores, 2005 b. 253-266.

,"El derecho penal liberal y sus enemigos." En torno a la cuestión penal. Buenos Aires: Euros Editores, 2005c. 153-177.

, El enemigo en el derecho penal. Buenos Aires: Ediar, 2009.

, "Derecho penal y protesta social." ¿Es legítima la criminalización de la protesta social? Derecho penal y libertad de expresión en América Latina, Eduardo Bertoni Ed. Buenos Aires: Universidad de Palermo, 2010. 1-15.

ZAFFARONI, Raúl Eugenio, Alagia,Alejandro, Slokar, Alejandro. Derecho Penal. Parte General. Buenos Aires: Ediar, 2002. 